\title{
Understanding Impacts of Service Robots with the Revised Gap Model
}

\author{
Shengliang Zhang ${ }^{1}$, Chaoying Huang ${ }^{1}{ }^{\mathbb{D}}$, Xiaodong $\mathrm{Li}^{2,3, * \mathbb{D}}$ and Ai Ren ${ }^{4}$ \\ 1 School of Management, University of Science and Technology of China, Hefei 230026, China; \\ shlzh@ustc.edu.cn (S.Z.); joyin@mail.ustc.edu.cn (C.H.) \\ 2 School of Economics and Management, Anhui Polytechnic University, Wuhu 241000, China \\ 3 School of Management, Zhejiang University, Hangzhou 310058, China \\ 4 School of Business, State University of New York at New Paltz, New Paltz, NY 12561, USA; \\ rena@newpaltz.edu \\ * Correspondence: lixiaodong@ahpu.edu.cn; Tel.: +86-553-2871256
}

check for updates

Citation: Zhang, S.; Huang, C.; Li, X.; Ren, A. Understanding Impacts of Service Robots with the Revised Gap Model. Sustainability 2022, 14, 2692. https://doi.org/10.3390/su14052692

Academic Editors: Maro

Vlachopoulou, Michael Bourlakis and Efthymios Constantinides

Received: 22 January 2022

Accepted: 22 February 2022

Published: 25 February 2022

Publisher's Note: MDPI stays neutral with regard to jurisdictional claims in published maps and institutional affiliations.

Copyright: (c) 2022 by the authors Licensee MDPI, Basel, Switzerland. This article is an open access article distributed under the terms and conditions of the Creative Commons Attribution (CC BY) license (https:// creativecommons.org/licenses/by/ $4.0 /)$.

\begin{abstract}
The service quality gap model, which identifies the antecedents of SERVQAUL, reveals that service quality depends on the gap between customer perceived and expected service (Gap 5), which can be caused by other gaps in the service process (Gaps 1-4). The emergence of service robots has affected the quality of services provided; however, little is known about how these impacts happen. Thus, this paper aims to explore the impacts of service robots on service quality by revising the original gap model in the context of robot service. This paper reviews and analyzes the literature related to service robots and develops a revised gap model for robot service by integrating the existing research on the impacts of service robots. By introducing the roles of robots and robot manufacturers into the original gap model, the revised gap model adds three new gaps: Gap 6 (manufacturers' understanding gap), Gap 7 (technical gap), and Gap 8 (service coordination gap). Based on the revised gap model, the impacts of service robots on service quality are expounded (i.e., Gap 5 can be affected by not only Gaps 1-4 but also Gaps 6-8), and several propositions are introduced. This paper is the first to consider robot manufacturers as part of the service quality gap model, and the first to use a dynamic model to explore the impacts of service robots on service quality. This paper not only supplements the service robot and gap model literature but also provides service companies with a meaningful framework to improve service quality when using robots to provide service.
\end{abstract}

Keywords: service robot; gap model; service quality; service delivery; robot manufacturer

\section{Introduction}

Robotics has developed into a multibillion-dollar industry, with robots being used in many work settings. Given the huge advantages industrial robots have offered, companies are gradually applying robots to the service sector [1]. According to van Pinxteren et al. [2], more than 6.7 million service robots are in operation, performing tasks that include providing information to hotel guests [3], taking orders in restaurants [4], and assisting customers in stores.

The implementation of service robots is a technological innovation that changes customer experience [5-7]. For example, service robots can provide customers with personalized service and product recommendations based on their past purchase behaviors [8]. A robot butler can order breakfast according to a guest's past preferences before he arrives at the hotel restaurant, saving his time in waiting for breakfast [9]. Nevertheless, suboptimal service robot performance may lead to customers' negative responses [9]. For instance, three restaurants in China "fired" their robot staff because of poor service and high customer dissatisfaction [10]. Because customers' evaluations of and satisfaction with service experience are related to their perceived service quality [10], it is critical for service companies to understand why and how these robots affect service quality. 
The emergence of service robots has attracted great attention within academia, and many researchers have clarified the impacts of service robots [2,11-13]. However, existing studies only consider the results of the service process without considering how robots affect service quality through their influence on the service process. For example, Belanche et al. [14] suggested that robot design and service encounter characteristics resulted in customer satisfaction and loyalty to the service provider. While they identified some key factors, they did not elaborate on how these factors play a role in the service process. Research and practice have also proven that the application of service robots affects different service roles in different ways. For example, service robots provide new opportunities for companies to reorganize organizational frontlines [8], which has automated many parts of service and freed human employees from trivial work [8]. Robot KeJia assists shopping mall customers by acting as a guide, providing information and entertainment [15]. However, since existing models only consider part of service roles, they are not comprehensive enough to address the full landscape of robot service. For example, Bolton et al. [11] developed a framework to analyze customer experiences at the intersection of the digital, physical, and social realms, which only considered the impacts of robots on customers. Huang and Rust [16] only acknowledged the effects of service robots on human employees by developing a theory of AI job replacement.

As Parasuraman et al. [17] observed, the discrepancy between customers' perceived service quality and their expectations is caused by a series of gaps during the service process. Thus, the service process can be clearly measured through gap analysis, which has been shown to be effective for improving service quality [18]. Meanwhile, the original gap model includes all the roles involved in the service process, which is helpful in a systematic study of how service robots affect all these roles and, ultimately, service quality. It is worth noting, however, that robots are the participants in the service process that have no agency of their own, with their social and technical performance instead guided by a third party that has traditionally remained external to the service process: manufacturers that design and produce service robots [19]. To date, no study has yet considered service robot manufacturers in the service process. Therefore, it is necessary to add this role to the original gap model, thus revising it to adapt the robot service scenario.

Beginning with reviewing and analyzing the literature related to service robots, our pioneering contribution is to revise the original gap model to offer a better understanding of the impacts of service robots on service quality by adding two roles (i.e., service robots and manufacturers) and three new gaps (i.e., Gaps 6-8). This paper makes three contributions. First, the uniqueness of this study is that it is the first study to introduce robot manufacturers into a conceptual model to analyze the impacts of service robots on service quality. Second, we revise the original gap model by identifying three new gaps and analyze the impacts of service robots on the eight gaps. The revised gap model in our study provides a more macroscopic and dynamic perspective for understanding the impacts of service robots on the whole service process, which is different from static models in existing studies. Third, this paper provides service companies with a meaningful framework to improve service quality when using service robots, as well as offering a clear direction for future researchers to empirically verify the impacts of service robots on service quality.

\section{Literature Identification and Collection}

This paper uses a traditional method to identify relevant articles for literature review. Articles related to service robots are obtained by searching databases and important journals, following the process adopted by Zhang and Benyoucef [20]. We first select some academic databases, including EBSCO, Elsevier Science Direct, Emerald, INFORMS, SAGE, Scopus, Springer, Web of Science, and Wiley Online Library, and we search these databases using keywords like robot, robotic, service robot, robot service, social robot, and humanlike robot. Second, we search important journals individually to avoid missing relevant articles. We conduct the same keyword search on marketing journals like Journal of Consumer Research, Journal of Marketing, Journal of Marketing Research, and Marketing Science, as well 
as service journals like Journal of Service Management, Journal of Service Marketing, Journal of Service Research, and Journal of Service Theory and Practice.

This paper follows the traditional literature review method to cross-check and verify the relevance of the initial set of articles. In order to separate relevant from irrelevant articles, we manually check the title, abstract or content of the article, determining relevance through two criteria: (1) relevant articles address the context of robot service and (2) relevant articles focus on the impacts of the service robots.

This process results in a total of 57 articles collected for the literature review. As shown in Figure 1, the number of articles about the impacts of service robots has gradually increased in the past ten years. This growth suggests that this is a new research area that is increasingly attracting academic interest. Note that the statistics of this year are not included since it has not yet ended. Table 1 shows a list of six journals and two magazines that printed more than one relevant article, suggesting that they have an interest in publishing on this topic. Journal of Service Research $(n=4)$ is the journal with the highest number of published articles, and Harvard Business Review $(n=6)$ is the magazine with the highest number of published articles. It is worth noting that most of the top journals in the service field have expressed research interest regarding service robots.

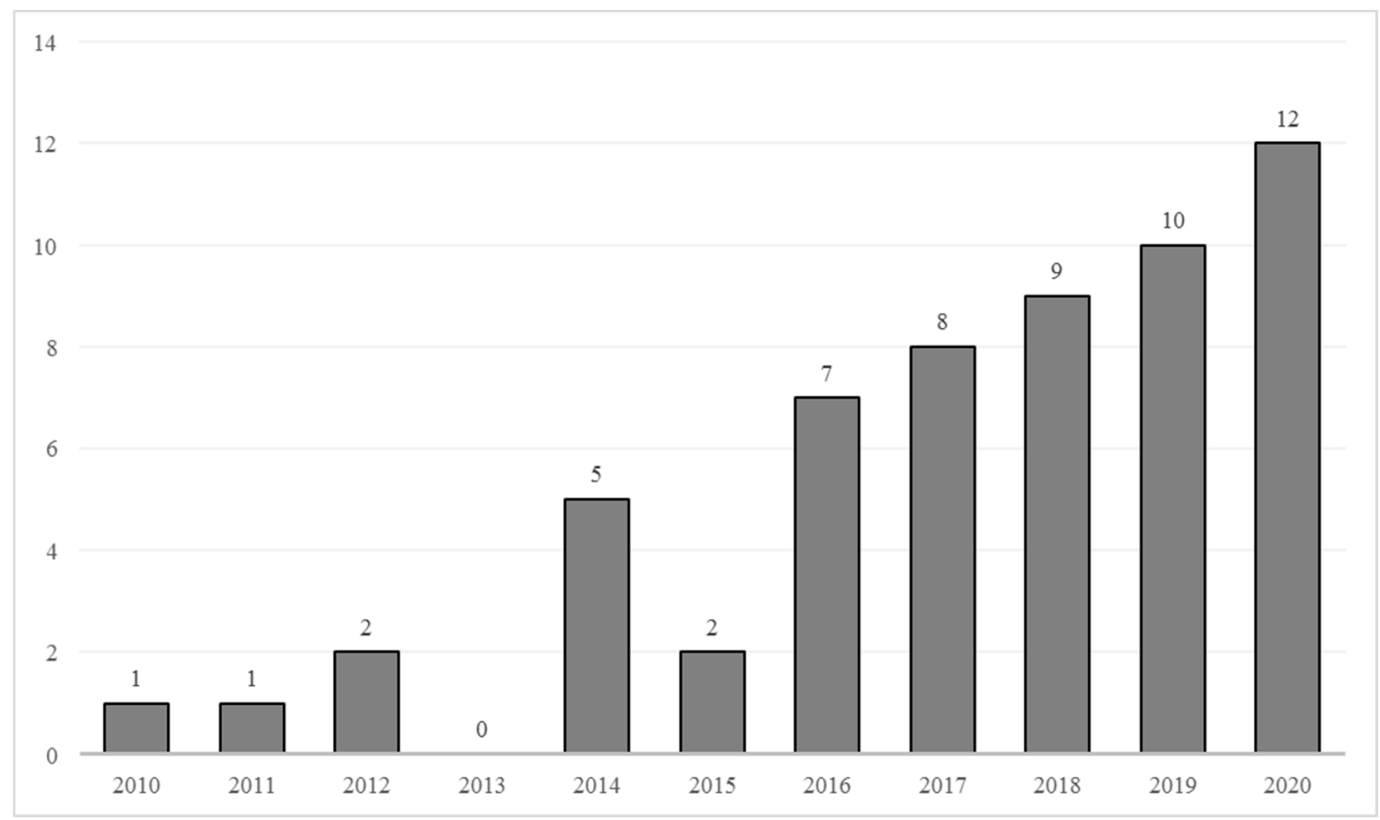

Figure 1. Publication timeline of related articles.

Table 1. List of journals and magazines with more than one article.

\begin{tabular}{|c|c|c|}
\hline Journal & Number & Source \\
\hline International Journal of Advanced Robotic Systems & 2 & Chen et al. [15], Qing-Xiao et al. [4] \\
\hline $\begin{array}{l}\text { International Journal of Contemporary } \\
\text { Hospitality Management }\end{array}$ & 3 & Kuo et al. [1], Tung and Au [21], Tung and Law [22] \\
\hline Journal of Hospitality Marketing \& Management & 3 & Fan et al. [23], Qiu et al. [6], Yu [24] \\
\hline Journal of Service Management & 3 & Bolton et al. [11], De Keyser et al. [25], Wirtz et al. [26] \\
\hline Journal of Service Research & 4 & $\begin{array}{l}\text { Huang and Rust [16], Jörling [5], van Doorn et al. [19], } \\
\text { Xiao and Kumar [27] }\end{array}$ \\
\hline Journal of Services Marketing & 2 & Čaić et al. [28], van Pinxteren et al. [2] \\
\hline Magazine & Number & Source \\
\hline Harvard Business Review & 6 & $\begin{array}{l}\text { Beane [29], BenMark and Venkatachari [30], } \\
\text { Brooks [31], Davenport and Ronanki [32], Forlizzi [33], } \\
\text { Zeller and Smith [34] }\end{array}$ \\
\hline MIT Sloan Management Review & 2 & Lacity and Willcocks [35], Ransbotham et al. [36] \\
\hline
\end{tabular}




\section{Review of the Studies}

In our review of each study, this paper focuses on three major aspects of each: (1) the concept of service robots, (2) the impacts of service robots, and (3) the reflection of robots' impacts in the gap model. We discuss the first two aspects in this section, and the third aspect is explained in the next section where we discuss the revised gap model.

\subsection{Concept of Service Robots}

The International Standards Organization defined service robots as robots that performs useful tasks for humans or equipment [37]. Current studies are continuing to extend this brief definition by using specific titles, which are complex and lack unity, and only focus on a particular role or function of the robot. A further examination reveals that these titles address three perspectives on robot service: those of customers, robot manufacturers, and human employees.

First, "humanoid robot" [13,38-40] and "social robot" [41-44] are terms used to refer to service robots from the perspective of customers. These descriptors emphasize customers' perception of the appearance and actions of service robots, as well as the functions of service robots in communicating, socializing with customers, and providing emotional support during the service provision process. Second, the terms "automatic device" [45] and "mechanical device" [14] emphasize the fact that a service robot is an autonomous intelligent service terminal device that can perform real tasks. They highlight the technical attributes of service robots from the manufacturers' perspective. Third, "robotic assistant" [12,27] and "digital assistant" [11] emphasize that a service robot, as a quasi-employee, can replace human beings in completing basic or daily services. These reflect the auxiliary and substitute role of service robots from the perspective of human employees.

In a dynamic service process, service robots have to face customers, human employees, and manufacturers at the same time. Therefore, the above descriptions are not comprehensive when considering the complete service delivery chain. To address this deficit and consider the dynamic nature of the service process, this paper combines the above three types of descriptions and further expands the definition of service robots proposed by Wirtz et al. [26]. We construe the service robot as a service contact device based on systematic, intelligent, autonomous, and adaptive technology, one that can interact with the organization's customers in a humanoid way (e.g., appearance, action, and communication) to complete various service functions so as to play the role of a service provider in the service delivery chain. This definition emphasizes that a service robot is an intelligent technical device designed by manufacturers. Since robots can provide service to customers in a humanoid way, they can be used to fill a variety of service labor roles previously undertaken only by human beings. This definition simultaneously takes into account the characteristics of service robots in light of their relationships with manufacturers, customers, and human employees, so these characteristics can be better applied in the revised gap model proposed later.

\subsection{Impacts of Service Robots}

There are two main literature streams related to the impacts of service robots (see Table 2). One relates to the antecedents of their impacts on customer experience. Specifically, some studies have analyzed the impacts of service robots based on their physical, functional, and social attributes. For example, in terms of physical attributes, Gursoy et al. [46], van Pinxteren et al. [2], and $\mathrm{Yu}$ [24] have mentioned the impacts of service robots' anthropomorphism on customers. Tung and Au [21], van Pinxteren et al. [2] and Wirtz et al. [26] mentioned that the functional attributes of service robots, like gaze turn-taking cues, could affect customers' attitudes. Social attributes such as interaction $[13,27]$ and relationship establishment [6] between service robots and customers could also affect customers' emotions. 
Table 2. Literature on the impacts of service robots.

\begin{tabular}{|c|c|c|c|}
\hline \multicolumn{4}{|c|}{ Research Stream: Antecedents of the Impacts of Service Robots on Customers } \\
\hline \multicolumn{2}{|c|}{ Antecedent } & Example & Source \\
\hline \multirow{3}{*}{ Robot attributes } & Physical attributes & Anthropomorphism. & $\begin{array}{l}\text { Bolton et al. [11], Gursoy et al. [46], } \\
\text { van Pinxteren et al. [2], } \\
\text { Xiao and Kumar [27], Yu [24] }\end{array}$ \\
\hline & Functional attributes & Gaze turn-taking cues. & $\begin{array}{l}\text { Bolton et al. [11], Tung and Au [21], } \\
\text { van Pinxteren et al. [2], Wirtz et al. [26] }\end{array}$ \\
\hline & Social attributes & $\begin{array}{l}\text { Interaction; rapport building; social emotional; } \\
\text { relational elements. }\end{array}$ & $\begin{array}{l}\text { Bolton et al. [11], Mende et al. [13], } \\
\text { Qiu et al. [6], van Pinxteren et al. [2], } \\
\text { Wirtz et al. [26], Xiao and Kumar [27] }\end{array}$ \\
\hline \multicolumn{2}{|l|}{ Customer perception } & $\begin{array}{l}\text { Perceived warmth and competence; perceived } \\
\text { effort expectancy; perceived behavioral } \\
\text { control; perceived ownership; perceived } \\
\text { human-orientation; perceived security and } \\
\text { co-experience; perceived intelligence } \\
\text { and safety. }\end{array}$ & $\begin{array}{l}\text { Čaić et al. [28], Gursoy et al. [46], } \\
\text { Jörling [5], Tung and Au [21], Yu [24] }\end{array}$ \\
\hline \multicolumn{4}{|c|}{ Research Stream: Impacts of Service Robots on Different Service Roles } \\
\hline \multicolumn{2}{|c|}{ Impacts on Service Role } & Example & Source \\
\hline \multirow{3}{*}{ Impacts on customers } & Customer experience & Hospitality experience; service experience. & $\begin{array}{l}\text { Qiu et al. [6], Tung and Au [21], Xiao and } \\
\text { Kumar [27], Yu [24] }\end{array}$ \\
\hline & Customer attitudes & $\begin{array}{l}\text { Dissatisfaction; emotion; acceptance; } \\
\text { discomfort; satisfaction; loyalty; engagement; } \\
\text { well-being; trust; enjoyment; intention to use. }\end{array}$ & $\begin{array}{l}\text { Fan et al. [23], Gursoy et al. [46], } \\
\text { Mende et al. [13], van Doorn et al. [19], } \\
\text { van Pinxteren et al. [2], Wirtz et al. [26], } \\
\text { Xiao and Kumar [27] }\end{array}$ \\
\hline & Customer behaviors & $\begin{array}{l}\text { Evaluation; compensatory responses; actual } \\
\text { use; degree of adoption. }\end{array}$ & $\begin{array}{l}\text { Čaić et al. [28], Mende et al. [13], } \\
\text { Wirtz et al. [26], Xiao and Kumar [27] }\end{array}$ \\
\hline \multirow[b]{2}{*}{$\begin{array}{l}\text { Impacts on human } \\
\text { employees }\end{array}$} & Threats & $\begin{array}{l}\text { Losing control over schedules and work tasks; } \\
\text { negative consequences for autonomy, visibility, } \\
\text { dependence, and morale; moving away from } \\
\text { "learning edge"; distancing from the work; } \\
\text { mastering both old and new methods; being } \\
\text { substituted in each type of task/job; negative } \\
\text { psychological outcomes; job insecurity. }\end{array}$ & $\begin{array}{l}\text { Barrett et al. [47], Beane [29], } \\
\text { Huang and Rust [16], Lu et al. [12] }\end{array}$ \\
\hline & Opportunities & $\begin{array}{l}\text { Expanding jurisdictions, expertise, and } \\
\text { professional standing; promoting occupational } \\
\text { authority and prestige; increasing skills and } \\
\text { agentic opportunities; seeking struggle; } \\
\text { redesigning roles; curating solutions; learning } \\
\text { from shadow learners; reducing routine work; } \\
\text { enhancing productivity and job satisfaction; } \\
\text { opportunities for human-robot collaboration. }\end{array}$ & $\begin{array}{l}\text { Beane [29], Huang and Rust [16], } \\
\text { Lu et al. [12] }\end{array}$ \\
\hline
\end{tabular}

From the perspective of customer perception, some studies have considered the impacts of perceived warmth and competence [6], perceived behavioral control [5], perceived human-orientation [21], and perceived intelligence and safety [24] on customer experience. Yet whether these studies adopt the perspective of robot attributes or customer perception, they only analyze the impacts of service robots from a static perspective, without considering the dynamics of the service process. A dynamic service process includes multiple links such as market research, service design, and service delivery [17]. Existing studies only consider the impacts of service robots in the service delivery link, failing to dig deeper into how these impacts were produced.

Another stream concerns the impacts of service robots on different service roles. Some have explored the impacts of service robots on customer experience [6,21,24], attitudes $[19,23,46]$, and behaviors $[13,27,28]$. For example, Qiu et al. [6] investigated the impact of service robot attributes on customers' hospitality experience, indicating that humanlike or intelligent qualities positively affect customers' hospitality experience. Wirtz et al. [26] built a model to illustrate the impacts of service robots on customer acceptance. Čaić et al. [28] considered 
social robots in elderly care service and outlined ways in which their humanlike affect and cognition influence users' evaluations.

Others have shown that service robots provide both threats and opportunities to human employees. On the one hand, the application of service robots makes employees think they have lost their autonomy at work [47], and working with robots requires them to learn more operational skills, which can cause difficulties [29]. On the other hand, robots can take on some trivial and repetitive tasks, allowing employees to devote more energy to creative work, thereby increasing productivity and job satisfaction [16].

However, most of these studies discuss the impacts of service robots on different roles separately, instead of considering them simultaneously in a complete framework. Based on a review of the previous literature on the impacts of robots on customers and employees, Lu et al. [12] put forward a future research framework for robot service encounter, which comprehensively expounded the impacts on customers from pre to post service, as well as on the organization and development of human employees. Moreover, Wirtz et al. [26] pointed out that service robots are developed and built by manufacturers who sell frontline service solutions to service organizations. In the course of the entire service process, robots face not only customers and human employees but also manufacturers, service companies, and other players. Therefore, a more complete model is needed, one that includes all roles at the same time.

In summary, the findings of existing research are scattered and subject to three limitations. First, current research about antecedents of the impacts of service robots focuses on the link of service delivery from a static perspective. There is no research from a dynamic perspective, investigating how service robots affect the customer experience through their influence on the service process. Second, although service robots may affect all roles within the service process (e.g., service companies, human employees, and customers), existing studies address these roles separately, and there is no unified examination of the impacts on all of these roles. Third, the findings of existing research are fragmented, and a more complete model is necessary to explain more fully the impacts of service robots on service quality. Therefore, this paper works to remove the limitations in the existing gap model.

\section{Development of the Revised Gap Model}

\subsection{Theoretical Background: The Original Gap Model}

The original gap model (see Figure 2) was proposed by Parasuraman et al. [17]. It explains how a company's service quality is formed and how other gaps in this process will affect the gap between the customers' expected service quality and their perceived service quality. The purpose of the model is to help companies identify possible problems in the service process and the reasons for those problems and then adjust to provide service quality that meets or exceeds customers' expectations [17]. Clearly, the original gap model has the potential to explain the impacts of service robots on service quality for two reasons. First, the gap model provides a clear and dynamic perspective for studying the impacts on the service process. Second, it allows us to integrate multiple service roles into the same discussion, which can make up for the limitations mentioned in the previous section.

However, technological advances have a profound impact on the nature of the organizational frontline [17], greatly changing the concept of a service provider, as well as the delivery of services [48]. We can see from Figure 3 that the application of service robots changes the original service delivery chain, which is composed of companies, human employees, and customers. Service robots also provide value in frontline service interaction [26]. For example, two robots make cocktails for customers on the Symphony of the Seas cruise ship [49]. A robot barista can serve up to 120 coffees per hour [50]. In the service encounter, the users who interact with the robots are not only the customers but also the human employees [27]. Dispensing robots, for example, cooperate with pharmacist assistants to bag and distribute drugs [47]. In addition, the success of service robots depends not only on downstream customers but also on the support of upstream manufacturing [1], since service robots execute algorithms programmed by manufacturers to complete tasks [8]. 
Manufacturers need to collect technical requirements from service companies in order to build robot prototypes and field-test them over multiple iterations until most issues are solved.

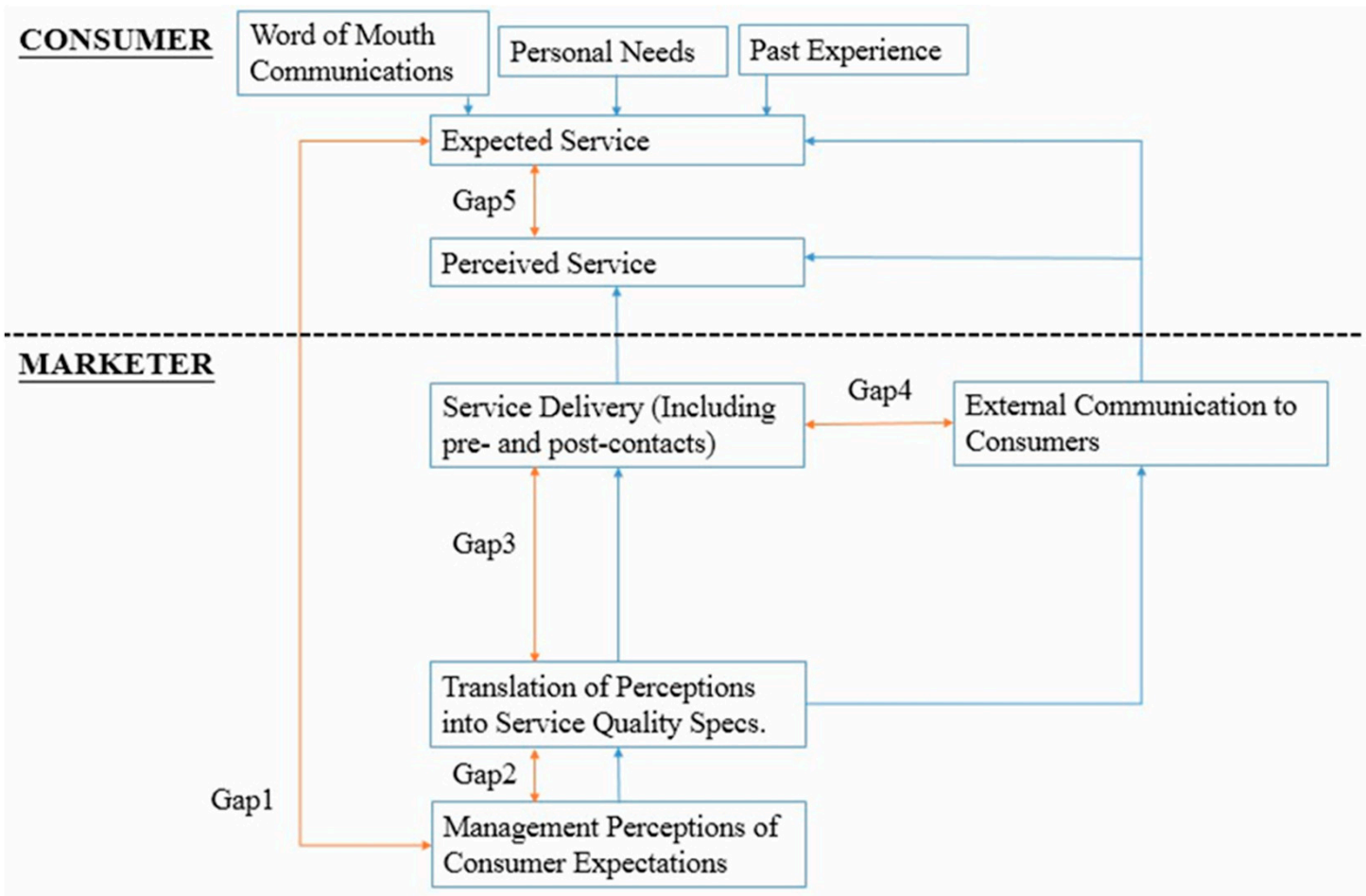

Figure 2. The original gap model.

\section{Original Service Delivery Chain}

Service Companies $\longrightarrow$ Human Employees $\longrightarrow$ Customers

\section{$\underline{\text { New Service Delivery Chain }}$}

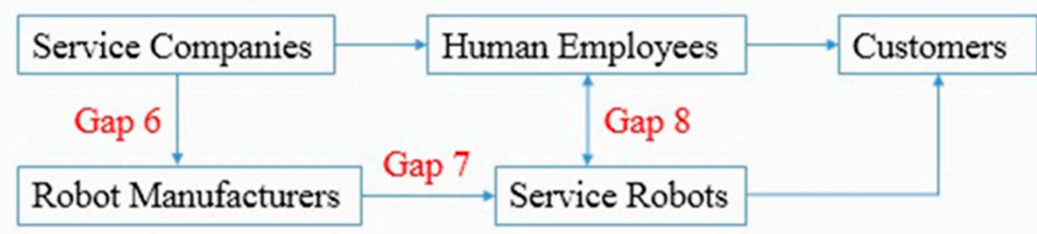

Figure 3. Changes in the service delivery chain.

Specifically, robot manufacturers need to cooperate with service companies [51] to understand how to produce robots that meet the companies' needs to avoid a manufacturers' understanding gap (Gap 6). Then, manufacturers need to establish effective interdisciplinary cooperation among service science, engineering, computer science, and other departments to solve the problems that arise when implementing robotic technology in a service context [52], to avoid a technical gap (Gap 7). Moreover, interaction with customers is considered one of the most critical determinants of service quality [46]. To a certain extent, service robots have replaced or cooperated with human employees. Thus, appropriate coordination between robots and human employees will have positive impacts on service quality; otherwise, a coordination gap (Gap 8) may arise. 
Through literature review, we find that previous studies' descriptions of the impacts of service robots reflect the impacts on certain parts of the original gap model or the emergence of new gaps (see Appendix A). These descriptions are detailed but are separate and micro, without clearly pointing out which gap in the service process they reflect. Thus, a more comprehensive model is needed to reflect the impacts of service robots on the whole service process, a deficit we aim to address through our revised gap model. We will elaborate on the revised gap model and on the impacts of service robots on service quality in the next two sections.

\subsection{The Revised Gap Model}

To better embody existing research about the impacts of service robots in a systematic framework, this paper proposes a revised gap model suitable for the robot service context (see Figure 4) by adding two links (i.e., "Robot Design/Manufacturer Understanding of Service Quality Specification" and "Robot Service Delivery"). The former refers to the robot manufacturer's understanding of the robot's quality specifications (e.g., appearance, performance, and cost) as required by service companies. The latter refers to the service provided to customers by the service robots. Once these two links are added to the gap model, three new gaps related to robot service emerge.

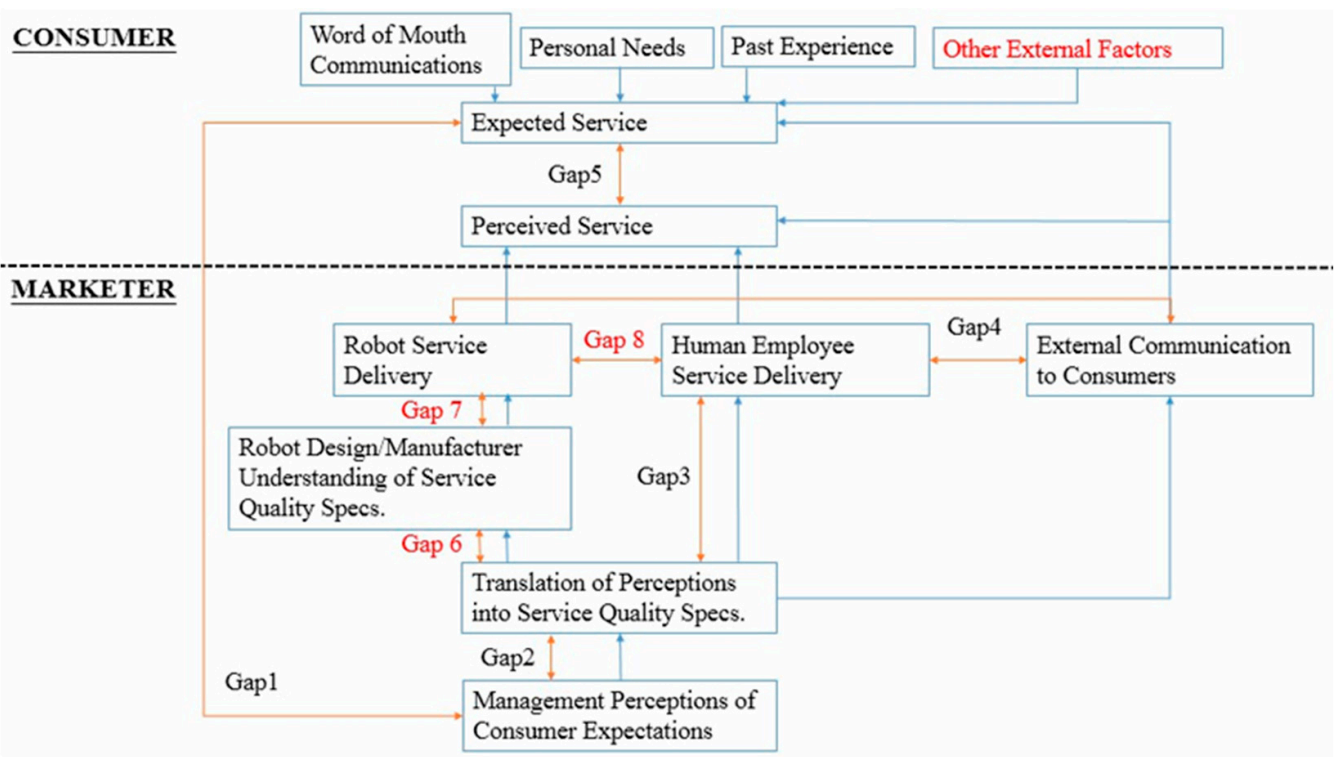

Figure 4. The revised gap model for robot service.

\subsubsection{New Gaps in Robot Service (Gaps 6-8)}

Gap 6, Manufacturers' Understanding Gap. At present, at least 25 countries have been involved in the manufacture of service robots, and nearly 300 robot manufacturers have begun operations. Different manufacturers focus on different fields, and the service robots produced are also very different in terms of performance. For example, iRobot's Roomba cleaning robot focuses on high-cost performance and popularization, while the American Da Vinci surgical robot focuses on high-tech precision manufacturing. Therefore, the selection of and communication with manufacturers has become a key link in the service process, one that is not accounted for in the original gap model. Service companies and robot manufacturers both have roles in the creation of a robotic control system, which, according to Zalama et al. [39], requires three levels of development: hardware, functionality, and service. Service is the expected capability of the service robot to meet the service company's requirements and create value for customers. The implementation of service depends on the hardware and functionality installed by the manufacturer. Because the service process is an interconnected whole, these three elements are influential throughout the process. Specifically, the service company determines the service quality specification 
for the service robot, such as the requirements for its appearance (the degree to which it is humanoid) and its functions (the type of service it can provide). Then, the manufacturer gets a clear understanding of the specification and produces robots that meet the requirements. Therefore, Gap 6 reflects a situation where manufacturers have difficulty understanding managers' service quality specifications.

Gap 7, Technical Gap. As we defined, service robots perform physical tasks autonomously through specific programming to provide service to customers. They perform tasks based on rules, relying on prior knowledge and continuous sensor perception to observe and respond to changes in the service environment [16], with little or no human intervention during execution [49]. In other words, when robots perform service delivery, as long as there is no technical failure or damage caused by external factors (e.g., power outage or breakage) or human causes (e.g., improper operation), they can complete service delivery in accordance with the procedures designed by manufacturers. However, in reality, the performance of service robots sometimes falls short of the expectations of service companies and manufacturers. For example, the burger-flipping robot at Cali Burger went offline after only one day of work because it was too slow [53]. The grocery store robot Fabio was considered a failure because it could not understand customers' problems [54]. Gap 7 reflects a situation in which service robots fail to provide service according to the service quality specifications understood by the manufacturers, which cannot be reflected through the original gap model.

Gap 8, Service Coordination Gap. When service robots replace part of human work, customers may be keenly aware of whether the service robots can equal or exceed human employees' level of service provision [46]. For service providers, the effect of emotion has become a critical consideration in customer satisfaction [55]. Contagion theory states that different emotions have different influences on customer satisfaction [55], and overall service quality depends on how a customer feels or how they interpret their emotions [56]. Therefore, we believe that comparing the emotional work of robot and human employees is very likely to affect customers' perceived service quality. When customers believe that the emotional effect of a service encounter with a robot is superior to the emotional effect of an encounter with a human employee, customer perceptions of robot service quality will improve. Whether this kind of replacement is effective largely depends on how managers divide emotional work between robots and human employees.

Practitioners' reports increasingly acknowledge that the highest performance gains occur when human employees work with machines, rather than when machines completely replace humans [25]. For example, the goal of a robot barista is not to replace human baristas, but rather to empower human baristas by taking over more routine operations. The human baristas can focus on providing high-quality service and facilitating the "coffee education" [50]. Tung and Law [22] point out that the success of a service robot depends on effective human-robot interaction, which relies largely on the work allocation of service companies. Whether it involves comparison of robot and human employees' emotional work or human-robot cooperation, service companies need to allocate work tasks effectively. Gap 8 reflects a situation where the service company has carried out the wrong human-robot work coordination, resulting in customers' negative experience of the robot service provision.

\subsubsection{Original Gaps in Robot Service (Gaps 1-4)}

In addition to the new gaps, we observe that the four gaps of the original model remain applicable in situations where service robots are introduced. Below, we update our understanding of these gaps to include contexts where service robots are present.

Gap 1, Managers' Understanding Gap. Gap 1 occurs when management does not correctly perceive or explain the customers' expectations for service robots. According to Verhoef et al. [57], organizations must account for customers' expectations about organizationbased resources in order to design service experiences for customers. Pino et al. [58] emphasized that the most critical barriers to robot acceptance reflect a mismatch between 
what is offered and what is expected. As a new technology, service robots have become an important resource, but in order to make them a better match for customers' needs, managers must understand customers' motivations and their expectations and acceptance of service robots, according to Pino et al. [58].

Gap 2, Quality Specification Gap. Gap 2 reflects a situation in which management's understanding of customers' expectations has not been fully and correctly translated into specific service quality specifications. As McKinsey\&Company [59] suggested, reworking processes and organizations to accommodate automation will give business leaders opportunities to improve their performance and enter new markets. The existing literature indicates that service companies must redesign their service quality specifications for robots, which starts with understanding customers' expectations and then reconsidering the design of the overall customer journey [30].

Gap 3, Human Service Delivery Gap. Gap 3 arises when employees do not correctly translate service specifications into specific service delivery actions. Xiao and Kumar [27] proposed three key steps for integrating robots seamlessly into a service team: redesign the service program, reorganize the service team, and provide support functions. Redesigning the service program involves reworking service quality specifications. Reorganizing the service team requires managers to reallocate work between robots and human employees, which means that part of the human employees' workload will be replaced by robots. Providing support functions means that human employees take training courses to learn how to fix and maintain the robots to prevent and address malfunctions [47]. Thus, in the robot service context, the specifications for human employees may change significantly, which brings new difficulties for them in meeting requirements.

Gap 4, Service Communication Gap. Gap 4 reflects a situation in which the actual service delivery fails to fulfill the promise of the service company to its customers. For instance, service robots used by many companies are largely a publicity stunt, and their actual benefits for service performance have not been fully realized [6]. Kuipers [60] noted that in order for robots to become integrated into human society, robot designers need to try to minimize the risk of value destruction and ensure that they are trustworthy and that their intentions are good. Before implementing service robots, service companies need to tell customers about the range of services that robots can provide and also about the possible service failures. This kind of communication can shape customers' expectations and have an important impact on the introduction of robots [41].

When service robots are applied, it is necessary for organizations to redesign their workflows [32]. Our revised gap model provides a framework for organizations to systematically review service processes when introducing service robots, helping them to become more aware of what pitfalls should be avoided in each link and, ultimately, to provide high-quality services for customers. In the next section, drawing on the revised gap model, we elaborate on the impacts of service robots on service quality.

\subsection{The Impacts of Service Robots Explained through the Revised Gap Model}

As previously discussed, the application of service robots not only changes the original service chain and creates new gaps but also affects our understanding of the original gaps. As Čaić et al. [28] observed, using service robots can create a positive service experience, but there is also the risk that an existing service experience may be destroyed. Therefore, the impacts of service robots may be positive or negative. In this section, we analyze the impacts of service robots on service quality through the revised gap model and put forward eight propositions.

\subsubsection{Impacts on the Original Gaps (Gaps 1-4)}

Impacts on Gap 1, Managers' Understanding Gap. Čaić [41] pointed out that many service providers innovate solely on their vision of the look, feel, and capabilities of new technology. They thus impose their idea of what a technology should be on customers, who might have different needs, desires, and expectations of technology-enhanced services. With the 
application of service robots, some managers may think that they understand customers' needs and may not invest in market research. Then, when the company tries to meet an incorrectly understood or nonexistent demand or benefit [61], their actions will inevitably have a negative impact on service quality. As Gursoy et al. [46] noted, investing blindly in artificial intelligence (AI) technology without knowing whether customers are willing to accept the use of AI devices may lead to wasted resources and even loss of customers. Thus, researchers are exploring customers' expectations for service robots. For example, through in-depth interviews, Caić [41] studied the views of elderly patients on nursing robots in order to provide a valuable reference for designing robots that meet patients' expectations. However, even when company management attempts to understand customer expectations, they may face several difficulties, as described below.

First, Holden and Karsh [62] state that from the perspective of the technology adoption lifecycle, people's acceptance of robot applications is still in the immature stage. In fact, a preponderance of evidence suggests that customers know little about service robots [11]. The general public rarely has the opportunity to interact with advanced robots in person, which leads to the sociotechnical blindness discussed by Johnson and Verdicchio [63]. Moreover, Belanche et al. [14] suggested that many customers feel awe or fear in the face of a novel disruptive technology. For example, due to their limited experience with robots, many customers are skeptical about interacting with them [8]. McKinsey\&Company [59] also indicated that people may feel uneasy about robots because robots replace human interaction in some intimate living environments. Johnson and Verdicchio [63] described this uneasiness as confusion about perceived autonomy, which, combined with sociotechnical blindness, can make customers anxious about service robots [63]. Since this kind of anxiety is not conducive to customers expressing their expectations of service robots, it becomes difficult for management to understand customers' expectations. Thus, managers may apply service robots according to their own ideas, which may eventually lead to a substantial gap between customers' perceived service quality and expectations.

However, practical evidence shows that after customers start to interact with service robots and find them useful, they are more willing to accept them [33,34,64,65]. For example, Bartneck et al. [66] found that the more people get used to robots, the more their knowledge and expectations are likely to change. Virabhakul and Huang [67] pointed out that after acquiring the direct experience and knowledge of AI devices used in service delivery, customers are more likely to accept their existence in service encounters. Therefore, we believe that when customers gradually increase their contact with service robots, their sociotechnical blindness and confusion about perceived autonomy will gradually weaken, and their expectations of the service robot will be more accurate, thus weakening the negative effects. Therefore, we make the following proposition:

Proposition 1. With the application of service robots, Gap 1 will be increased (i.e., difficult for management to understand the expectations of customers) due to customers' sociotechnical blindness and confusion about perceived autonomy, which can be bridged by customers' increased contact with service robots.

Impacts on Gap 2, Quality Specification Gap. As Parasuraman et al. [17] noted, just because managers have knowledge of customer expectations does not mean that they have the ability to deliver to those expectations. Robot technology is not yet fully mature, and there are gaps between existing technology and customers' expectations [15]. Broadbent [68] stated that with current technology it is difficult to create autonomous robots. As Huang and Rust [16] indicated, the AI market is currently dominated by mechanical AI and analytical AI, and while there is a trend toward intuitional AI, empathetic AI accounts for a very minor or even negligible proportion of the AI available. Although Caić [41] was able to use in-depth interviews to identify three types of functions that elderly people want a nursing robot to have (i.e., safeguarding, social contact, and cognitive support), it is difficult to realize these functions fully with the current technology. Therefore, when 
people expect robots that are beyond current technical capabilities, management cannot completely translate customers' expectations into realistic quality specifications.

Although the current state of technological development means that the intelligence of service robots is inadequate for some service tasks [21], Kuo et al. [1] indicated that these problems can be solved gradually as robot technology and robot design progress. Many scenarios show that current robot technology has largely met customers' daily needs. For example, Connie the robotic concierge addresses Hilton Hotels guests' needs for general information $[46,69]$. Robotics has also been changing healthcare value networks and assisting healthcare professionals in tasks such as surgery, telepresence, prevention, and chronic care [36]. Therefore, we make the following proposition:

Proposition 2. With the application of service robots, Gap 2 will be increased (i.e., difficult for management to transform the expectations into specifications) due to the mismatch between existing technologies and customer expectations, which can be bridged by the progress of robotics.

Impacts on Gap 3, Human Service Delivery Gap. In a context where robots have assumed some tasks, human employees have more time and energy to manage non-procedural affairs and provide personalized services [6]. Brooks [31] showed that as robots take over algorithmic tasks that are meaningless and inhumane, employees can focus on tasks that are more creative, innovative, interesting, and valuable. Lacity and Willcocks [35] put forward a similar view, stating that if robots complete all repetitive structured tasks, human employees will need more and more creativity, problem-solving skills, judgment, and emotional intelligence to deal with unique, urgent, or unstructured tasks. In a workplace interview conducted by Qiu et al. [6], it was found that compared with hurried employees without robot assistance, employees working with robots were more likely to smile and show patience. When human employees thus have positive attitudinal and behavioral responses to working with service robots, they can provide very effective service [27]. For example, in the research of Barrett et al. [47], dispensing robots helped pharmacists to free themselves from the ordinary work of dispensing, giving them more time to do research or consult with patients, ultimately improving their specialized medical field.

Nevertheless, it is difficult for all employees to comply with these specifications. If an employee's adaptability is poor, they may not be able to adapt to the great changes in work specifications brought about by the addition of service robots. This is why tens of thousands of people will lose jobs every year [29]. With the addition of robots, an employee's identity changes from service provider to service provider and supporter, leading to role ambiguities and role conflicts that cause them to be more confused by and unsuited to the new demands of their job, and making it harder for them to meet quality specifications. For example, in a scenario described by Barrett et al. [47], with the implementation of dispensing robots, in contrast with the experience of pharmacists who were relieved of their trivial work, pharmacists' assistants were subject to even more demands. They now needed to determine the proper location of items and load the robots and storage shelves. They sometimes worked during their break times in order to complete these new activities.

The application of service robots has different impacts on human employees with different identities. With highly skilled employees, service robots help to deal with more trivial tasks, reduce the possibility of making mistakes in these tasks, and let the employees better meet the demand for more creative, highly skilled work to provide customers with higher-quality services. However, Kuo et al. [1] pointed out that entry-level jobs, especially unskilled service tasks, will gradually be replaced by automation and robotics. Therefore, to remain in the workforce, employees who are less skilled must learn higher-level skills, from basic programming to technical troubleshooting [8], in order to collaborate better with robots. These employees are suffering from both physical and psychological pressure under the increasing requirements, so it may be difficult for them to meet quality specifications fully. Therefore, we make the following proposition: 
Proposition 3. With the application of service robots, Gap 3 will be decreased for high-skilled human employees (i.e., easy for them to meet the specifications), due to having more time and energy, and will be increased for low-skilled human employees (i.e., difficult for them to meet the specifications), due to having more tasks and roles, which can be bridged by upskilling.

Impacts on Gap 4, Service Communication Gap. Because stimulating customers' interest and curiosity can promote the adoption of service robots [1], many service companies exaggerate the functions of their service robots to attract customers' attention, which will increase the company's tendency to overcommit [61]. Another reason for overcommitment is inadequate internal communication between service companies and robot manufacturers. When the commitments service companies make to their customers are inconsistent with the requirements they provide to manufacturers, or when companies do not receive accurate information about the robots during the manufacturing process, the services that the robots actually provide may be different from the services publicized to customers.

Technological advancement is increasing the degree of anthropomorphism of robots, and the Turing test shows that in the future humans may not be able to tell whether they are interacting with humans or robots [70]. Despite this increasing anthropomorphism, a considerable number of customers reject interaction with robots. For example, Davenport et al. [49] found that if customers realize that they are interacting with robots, they may become uncomfortable, which can lead to negative consequences. Forlizzi [33] therefore emphasized that customers must be technically and psychologically prepared to use robot services. "Robot notification" will thus be necessary in external communication. As described by Belanche et al. [14], robot notification means notifying customers whether they are interacting with a robot or with a human. Robot notification can prevent the negative impacts of robot service failure because customers have higher tolerance for robot service failure than for human staff service failure. Therefore, we make the following proposition:

Proposition 4. With the application of service robots, Gap 4 will be increased (i.e., difficult for service delivery to keep companies' commitments) due to service companies' overcommitment and inadequate internal communication with manufacturers, which can be bridged by robot notification.

\subsubsection{Impacts on the New Gaps (Gaps 6-8)}

Impacts on Gap 6, Manufacturers' Understanding Gap. Service robots are newly emerging technology within the industry and the level of technology varies from manufacturer to manufacturer. For example, in the case of concierge robots, there are many manufacturers such as SoftBank, Ubisoft, and Cobos to choose from. If companies do not conduct adequate research before choosing a manufacturer, they cannot fully understand the manufacturers' capacity and level, and thus they choose a manufacturer that fails to match their expectations. Moreover, there may be a lack of effective internal communication between the company and the manufacturer. The company must fully inform its chosen manufacturer of the service quality specifications, and the manufacturer should evaluate whether the requirements can be met. If necessary, the service company should revise its service quality specifications on the basis of the manufacturer's feedback.

According to Belanche et al. [14], when the hospital worked with the manufacturer of a dispensing robot, experts and pharmacists visited the manufacturer to examine the robot and then suggested several changes to make the robot more relevant to hospital pharmacy practices. Only through such an exchange can a good match be established between the company's requirements and the manufacturer's abilities, ultimately resulting in service robots that meet all the requirements. Therefore, we make the following proposition:

Proposition 5. With the application of service robots, Gap 6 will be increased (i.e., difficult for manufacturers to understand specifications) due to insufficient research on and lack of effective 
internal communication with manufacturers, which can be bridged by closer collaboration with manufacturers.

Impacts on Gap 7, Technical Gap. This gap arises as a result of programming loopholes. As Kabadayi et al. [9] suggested, whether the service is conventional or intelligent, service failure is always possible; every device, machine, and robot that contributes to service delivery may fail at some time. Such loopholes in robot programming may cause Gap 7 and affect the customer service experience. One example comes from Henn-na Hotel in Japan, which eliminated about 250 service robots because of failures in the service delivery process: the robots mistakenly regarded guests' snoring as commands, and so they constantly woke up the sleeping guests [12]. There are many reasons for programming loopholes, such as a loss of high-end talent, a lack of professional training for manufacturers, an inability to produce key parts of robots, and an inability to manufacture sophisticated and commercial robots [1].

However, as robot technology continues to improve, the technical gap will gradually narrow, so robots will become more capable of providing services that meet customer expectations. There is growing evidence that when manufacturers work with the precision instrument industry and the ICT supply chain, more intelligent robots can be developed [1] Therefore, we make the following proposition:

Proposition 6. With the application of service robots, Gap 7 will be increased (i.e., difficult for robot service delivery to meet technical requirements) due to programming loopholes, which can be bridged by the progress of robotics.

Impacts on Gap 8, Service Coordination Gap. First, effective human-robot work coordination depends on whether managers have a clear grasp of the emotional characteristics of the service robots. The existing literature distinguishes between deep acting (when employees display true emotions) and surface acting (when employees display superficial, inauthentic emotional responses) [71]. Wirtz et al. [26] pointed out that in the foreseeable future, service robots are unlikely to have real emotions but can highly mimic surface emotions. Although these mimicked emotions may be sufficient for many types of mundane service encounters, in longer and high-engagement encounters, they may become more pronouncedly unreal [26], and so customers may be unwilling to respond to these emotions. Robots are thus better suited for roles where encounters are likely to be shorter, more routine, and less emotionally complex.

Another reason for Gap 8 is that human-robot cooperation is sophisticated [72], and cooperation failures can occur. For example, before a food delivery robot can deliver food, human employees need to put the food in the designated location and enter the correct table number for the customers. When a human employee makes a mistake (e.g., they do not know how to input the table number properly), service failure happens, leading to customer dissatisfaction. Ideally, robots enhance the capabilities of service agents and reduce their workload, thus achieving a better customer experience by simplifying interactions and providing relevant information at the right time; however, it is challenging to design service processes in which humans and robots are coordinated within the involvement of robots [9]. With the application of service robots, it is very important for an organization to deploy tasks properly and coordinate a cooperative relationship between robots and human employees. Therefore, we make the following proposition:

Proposition 7. With the application of service robots, Gap 8 will be increased (i.e., difficult for management to carry out human-robot work coordination) due to lack of understanding of robot characteristics and sophistication of human-robot cooperation, which can be bridged by correct human-robot work deployment. 


\subsubsection{Impacts on Service Quality (Gap 5) through Original and New Gaps}

Impacts on Gap 5, Service Quality Gap. As stated by Parasuraman et al. [17], gap analysis can serve as a starting point for complex service process control since all gaps eventually affect Gap 5 (i.e., the gap between customer expected service and customer perceived service). Specifically, in terms of original gaps, inability to understand customer expectations (Gap 1), formulate specifications in line with expectations (Gap 2), provide services in accordance with specifications (Gap 3), and provide services consistent with commitments (Gap 4) will all lead to a decrease in customer perceived service quality. As for new gaps, if a manufacturer cannot fully understand the company's quality specifications (Gap 6) or there are serious technical loopholes (Gap 7), the performance of robots will be inadequate, and the perceived service quality will decrease. Moreover, improper service deployment (Gap 8) will also reduce customers' perception of service quality. In sum, we use the following function to generalize the above relation:

Proposition 8. Gap 5 = F (Gap 1, Gap 2, Gap 3, Gap 4, Gap 6, Gap 7, Gap 8).

\section{Discussion}

\subsection{Key Findings}

Table 3 summarizes our research, including the explanations of and impacts on the new and original gaps, the reasons for these impacts, and ways to bridge these gaps. By reviewing the existing literature on service robots, our research starts from the perspective of the service delivery chain and revises the original gap model. Using the revised model, we discuss the impacts of service robots on service quality. Our findings provide a systematic perspective for understanding how service robots affect customers' perceived service quality throughout the whole service process.

First, since the application of service robots has changed the service delivery chain with participation of service robots and manufacturers, this paper revises the original gap model by adding two links and identifying three new gaps. We first identify Gap 6 and Gap 7, which incorporate the service robot manufacturer into the service process and address the resulting issues, exemplifying the view in the information technology field that robots provide services by executing algorithms programmed by engineers [8]. The status of manufacturers was also highlighted by Kuo et al. [1] when they analyzed the future development of the robotics industry by using a SWOT model. In addition, Gap 8 reflects the need for human-robot work coordination, which is consistent with the views of previous researchers [29,47]. For example, the dual service provision and humanmachine division of labor proposed by Huang and Rust [16] emphasize two approaches to work coordination between human employees and robots. Wirtz et al. [26] compared the characteristics of robots and human employees in order to better distinguish their abilities and carry out effective work coordination.

Second, following from these newly identified gaps, we elaborate on the impacts of service robots on service quality from the perspective of our revised gap model. For example, we posit that customers' sociotechnical blindness and confusion about perceived autonomy will increase Gap 1 to affect service quality, which is in line with the work of van Pinxteren et al. [2] and Xiao and Kumar [27], who indicated that customers' trust in and acceptance of a robot will drive their intention to use it. Gap 2 and Gap 7 both suggest that the advancement of robotics will affect service quality, which supports the opinions of Kuo et al. [1] and Huang and Rust [16] that different intelligent robots will have different impacts on service quality. The impacts we identify in Gap 3 and Gap 8 also reflect the views expressed in the research of Lu et al. [12], which generalized the employee benefits, potential negative consequences, opportunities, and development requirements brought by service robots. Likewise, the views reflected in the above five gaps also confirm the factors analyzed by Nam et al. [73], who used the Technology-Organization-Environment (TOE) model to identify factors such as technology, employee resistance, and consumer readiness and experience. The customers' expectations, robotics, and robot notification we identified 
in Gap 1, Gap 2, and Gap 4 partly reflect the expectancy, technology infrastructures, and continuous communication mentioned by Pandey et al. [74], who used the service adoption theory and the Unified Theory of Acceptance and Use of Technology (UTAUT) model to analyze the challenges of service technology adoption.

Table 3. Summary of the revised gap model.

\begin{tabular}{|c|c|c|c|c|}
\hline Gap & Explanation & Impact & Reason & Way to Bridge \\
\hline \multicolumn{5}{|c|}{ New Gap } \\
\hline $\begin{array}{l}\text { Gap 6: Manufacturers' } \\
\text { understanding gap }\end{array}$ & $\begin{array}{l}\text { A situation where } \\
\text { manufacturers have difficulty } \\
\text { understanding managers' } \\
\text { service quality specifications. }\end{array}$ & Increases & $\begin{array}{l}\text { Insufficient research on } \\
\text { manufacturers; lack of } \\
\text { effective internal } \\
\text { communication. }\end{array}$ & $\begin{array}{l}\text { Closer collaboration } \\
\text { with manufacturers }\end{array}$ \\
\hline Gap 7: Technical gap & $\begin{array}{l}\text { A situation where service } \\
\text { robots fail to provide service } \\
\text { according to the service quality } \\
\text { specifications understood by } \\
\text { the manufacturers. }\end{array}$ & Increases & $\begin{array}{l}\text { Robot programming } \\
\text { loopholes; lack of talent } \\
\text { and resources. }\end{array}$ & The progress of robotics \\
\hline $\begin{array}{l}\text { Gap 8: Service } \\
\text { coordination gap }\end{array}$ & $\begin{array}{l}\text { A situation where the service } \\
\text { company has carried out the } \\
\text { wrong human-robot } \\
\text { work coordination. }\end{array}$ & Increases & $\begin{array}{l}\text { Lack of understanding of } \\
\text { robot characteristics; } \\
\text { sophistication of } \\
\text { human-robot cooperation. }\end{array}$ & $\begin{array}{l}\text { Correct human-robot } \\
\text { work deployment }\end{array}$ \\
\hline \multicolumn{5}{|c|}{ Original Gap } \\
\hline $\begin{array}{l}\text { Gap 1: Managers' } \\
\text { understanding gap }\end{array}$ & $\begin{array}{l}\text { A situation where managers } \\
\text { have difficulty understanding } \\
\text { customers' expectations. }\end{array}$ & Increases & $\begin{array}{l}\text { Sociotechnical blindness } \\
\text { and confusion about } \\
\text { perceived autonomy } \\
\text { of customers. }\end{array}$ & $\begin{array}{l}\text { More contact with } \\
\text { service robots }\end{array}$ \\
\hline $\begin{array}{l}\text { Gap 2: Quality } \\
\text { specification gap }\end{array}$ & $\begin{array}{l}\text { A situation where managers' } \\
\text { understanding of customers' } \\
\text { expectations has been fully } \\
\text { and correctly translated into } \\
\text { specific service quality } \\
\text { specifications. }\end{array}$ & Increases & Limitations of robotics. & The progress of robotics \\
\hline \multirow{2}{*}{$\begin{array}{l}\text { Gap 3: Human service } \\
\text { delivery gap }\end{array}$} & \multirow{2}{*}{$\begin{array}{l}\text { A situation where human } \\
\text { employees do not correctly } \\
\text { translate service specifications } \\
\text { into specific service delivery. }\end{array}$} & $\begin{array}{l}\text { Decreases (for highly } \\
\text { skilled employees) }\end{array}$ & $\begin{array}{l}\text { Efficient use of time } \\
\text { and energy. }\end{array}$ & \\
\hline & & $\begin{array}{l}\text { Increases (for } \\
\text { low-skilled employees) }\end{array}$ & $\begin{array}{l}\text { Dual pressure of task } \\
\text { and roles. }\end{array}$ & Upskilling \\
\hline $\begin{array}{l}\text { Gap 4: Service } \\
\text { communication gap }\end{array}$ & $\begin{array}{l}\text { A situation where the actual } \\
\text { service delivery fails to fulfill } \\
\text { the promise of the service } \\
\text { company to its customers. }\end{array}$ & Increases & $\begin{array}{l}\text { Overcommitment of robot } \\
\text { service; lack of effective } \\
\text { internal communication. }\end{array}$ & Robot notification. \\
\hline Gap 5: Service quality gap & $\begin{array}{l}\text { A situation where customers' } \\
\text { perceived service quality } \\
\text { cannot meet their expectations. }\end{array}$ & \multicolumn{3}{|c|}{ Gap $5=F($ gap 1, gap 2, gap 3, gap 4, gap 6, gap 7, gap 8$)$} \\
\hline
\end{tabular}

\subsection{Theoretical Contributions}

In this paper, we revise the original gap model to study the impacts of service robots on service quality, making three contributions to the academic understanding of service robots.

First, this paper provides a revised gap model that is specifically adapted to the context of robot service, thus contributing to marketing theory. In particular, the model aims to shed light on current research regarding the impacts of service robots on service quality as perceived by customers, similar to the models proposed by van Doorn et al. [19], Wirtz et al. [26], and Xiao and Kumar [27]. However, in contrast with these previous models, which each focus on a single link in the service process from a static perspective, our model considers the possible impacts on each link of the service process dynamically. In view of the fact that the findings of previous studies are scattered and do not clearly indicate how they are reflected in the service process, this paper integrates those findings into a more comprehensive model and appropriately adds theoretical and practical support. 
Therefore, the revised gap model we propose can macroscopically illustrate the impact mechanism of the addition of service robots to the entire service process.

Second, no studies to date have emphasized the important position of manufacturers in robot service, and our findings bridge this research gap in the literature. Our model brings service robots and manufacturers into the scope of the service delivery chain, which gives a more complete view of the robot service process and makes up for the absence of robot manufacturers in the existing service marketing literature. As technology continues to progress, manufacturers' abilities will become the key factor in determining the success of intelligent machines. Considering the manufacturer thus helps enhance the generality of our model for different intelligent machine scenarios (e.g., virtual robots, AI devices and self-service technology). In addition, some existing studies only consider the impacts of service robots in specific scenarios, such as the hospitality industry [6], shopping malls [15], and hospitals [47]. Because any kind of service requires a service process, however, the proposed model has the power to explain how robots can be most effectively introduced into service contexts including hotels, restaurants, conferences, theme parks, and travel agencies [75]. In other words, our model has a certain degree of generality that makes it a supplement to and a means of advancing existing research.

Third, after comprehensively reviewing the literature on service robots, this paper elucidates the impacts of service robots from the perspective of the revised gap model, analyzing the possible reasons for robots' impacts on service quality. In contrast with the scattered explanations that can be found in the existing research, this paper puts forward reasons that accommodate the dynamics and continuity of the service process. For example, existing studies have discussed the impacts of service robots on customers and human employees separately [12]; however, in reality, the impacts of service robots on human employees (i.e., Gap 3 and Gap 8) may lead to additional impacts on customers (i.e., Gap 5). Compared with existing findings that adopt a static perspective, this paper puts humanrobot coordination in the context of a dynamic service process. This allows for a discussion that not only better explains the possible antecedents and consequences of human-robot coordination in the service process, but also better demonstrates the relationship between robot service and human employee service in the service process. Therefore, the revised gap model embodies the viewpoints of existing research more dynamically, thus more clearly demonstrating the impacts of service robots throughout the entire service process. It also provides a framework that future researchers can verify through quantitative analysis.

\subsection{Practical Implications}

In order to eliminate the negative impacts of Gaps 1-8 and improve service quality, this paper puts forward some managerial suggestions for business practitioners.

Managers to Customers (i.e., Reduce Gaps 1 and 4). To be informed of customers' expectations of robot service, managers can start by building awareness; customers who do not know enough about service robots can learn about them through certain channels. For example, managers can show customers videos of various service robots, and they can give customers priority in experiencing robot-provided service. Some customers cannot accept service robots, and in such cases, it is necessary to analyze the factors affecting customer acceptance of service robots by designing questionnaires. Robot notification is important in external communication to introduce service robots realistically in external publicity. If necessary, managers should inform customers in advance of the possible service failures of the service robots.

Managers to Service Robot Manufacturers (i.e., Reduce Gap 6). Before choosing a manufacturer, managers should have a full grasp of each candidate's production information, which can help them select the most cost-effective manufacturer. They should fully inform the selected manufacturer of the service quality specifications and follow up continuously to revise and adjust the specifications and external publicity in a timely manner. A company can also choose to develop service robots internally, which could involve conducting exter- 
nal recruitment, cooperating with scientific and technological universities to train robot engineers, or even setting up robot engineering schools.

Managers to Human Employees (i.e., Reduce Gaps 3 and 8). To make an appropriate deployment of frontline service work, managers can use service robots to replace humans in tasks with lower cognitive and emotional requirements. Moreover, service robots can collaborate with human employees to enhance service quality and efficiency. For example, compared to human employees manually searching for information from the system, robots can automatically connect to a backend internal knowledge base to obtain customer information and data, which can be shared with human employees to provide customized customer service together. Like some restaurant robots, they can automatically capture customers' past eating habits through facial recognition when greeting customers. Human employees then use the information automatically captured by the robots to recommend the preferred dishes for customers. At the same time, managers must both train their human employees in skills and help them adjust psychologically to working with robots.

Managers to Robot Technology (i.e., Reduce Gaps 2 and 7). Managers should pay careful attention to the development of robot technology so that they can formulate more accurate quality specifications for robot service and communicate more effectively with manufacturers. They should also be able to deal easily with possible failures in robot service delivery and take timely remedial measures, which is conducive to improving customers' perceived service quality.

\subsection{Limitations and Future Directions}

The findings of this paper still have some limitations, which provide directions for future research.

First, this study constructs the revised gap model based on qualitative methods, and the propositions lack support from empirical data. Researchers should empirically verify the new gaps in the revised gap model to confirm their existence and causes. At the same time, researchers should be aware that the impacts of various gaps on service quality may be positive or negative. Therefore, researchers can further test the relationships between the gaps and make additional improvements to our conceptual model.

Second, the model in this study is only proposed in the context of service robots, and its generality needs to be further verified. Researchers can test this model in different service scenarios and in scenarios with different intelligent devices. For example, the model can be tested in face-to-face and remote service scenarios, or in environments using physical robots and in those using virtual robots, AI devices, or autonomous technology services. Inclusion of a range of scenarios will be conducive to the development of the theory.

Third, although this paper adds robot manufacturers to the revised gap model, as the robot industry continues to grow, the process of taking a robot from design to application may become more complicated. For example, when a service robot is jointly developed by different manufacturers, the relationship between the manufacturers may bring new changes to the model. Therefore, researchers can revise and improve the sequential structure of this model after fully investigating the service robot industry. At the same time, the relationship between managers and manufacturers is like the relationship between customers and service companies, which can be well-suited to a hidden small gap model. In the future, researchers may consider incorporating a small gap model into our revised large gap model in order to make the overall conceptual model more complete.

Author Contributions: Conceptualization, S.Z.; formal analysis, C.H.; methodology, A.R.; project administration, X.L. All authors have read and agreed to the published version of the manuscript.

Funding: This research was funded by Anhui Philosophy and Social Science Planning Project, grant number AHSKY2017D24.

Institutional Review Board Statement: Not applicable.

Informed Consent Statement: Not applicable. 
Data Availability Statement: Not applicable.

Conflicts of Interest: The authors declare no conflict of interest.

\section{Appendix A}

Table A1. The embodiment of existing research in the revised gap model.

\begin{tabular}{|c|c|c|}
\hline Gap & Source & Viewpoint \\
\hline \multirow{14}{*}{$\begin{array}{l}\text { Gap 1: Managers' } \\
\text { understanding gap }\end{array}$} & Andreassen et al. [64] & $\begin{array}{l}\text { Low customer acceptance of robots; customers are not used to } \\
\text { trusting robots; customers prefer dealing with human employees } \\
\text { rather than robots. }\end{array}$ \\
\hline & Bartneck et al. [66] & $\begin{array}{l}\text { Customers' expectations may change when they get used to the } \\
\text { presence of robots. }\end{array}$ \\
\hline & Belanche et al. [14] & $\begin{array}{l}\text { Customers feel awe or fear in the face of a novel } \\
\text { disruptive technology. }\end{array}$ \\
\hline & Bolton et al. [11] & $\begin{array}{l}\text { Customers know little about automated social presence such } \\
\text { as robots. }\end{array}$ \\
\hline & Čaić [41] & $\begin{array}{l}\text { Service and technology developers impose their idea of } \\
\text { technology on customers who may have different expectations of } \\
\text { technology-enhanced services. }\end{array}$ \\
\hline & Chen et al. [15] & $\begin{array}{l}\text { Customers have little opportunity to interact with tangible } \\
\text { advanced robots in person. }\end{array}$ \\
\hline & Gursoy et al. [46] & $\begin{array}{l}\text { Blindly investing in the AI technology without understanding the } \\
\text { willingness of customers to accept it can lead to the waste of } \\
\text { resources and the loss of customers. }\end{array}$ \\
\hline & Holden and Karsh [62] & Customers' acceptance of robots is at an immature stage. \\
\hline & Johnson and Verdicchio [63] & Customers experience anxiety about service robots in real life. \\
\hline & Kuo et al. [1] & $\begin{array}{l}\text { the benefits of service robots; there is a big gap between customer } \\
\text { expectations and reality of service robots. }\end{array}$ \\
\hline & Paluch et al. [8] & $\begin{array}{l}\text { Customers are skeptical about interacting with robots; customers } \\
\text { have limited experience interacting with robots. }\end{array}$ \\
\hline & Pino et al. [58] & $\begin{array}{l}\text { The barriers to social robot acceptance reflect the mismatch } \\
\text { between what is offered and what is expected. }\end{array}$ \\
\hline & Tung and $\mathrm{Au}[21]$ & $\begin{array}{l}\text { Customers reported a shift from pre-interaction fear and } \\
\text { insecurity about robots to post-experience trust and comfort. }\end{array}$ \\
\hline & Virabhakul and Huang [67] & $\begin{array}{l}\text { Customers are more likely to accept AI devices after having direct } \\
\text { experience and knowledge of using them in service delivery. }\end{array}$ \\
\hline \multirow{6}{*}{$\begin{array}{l}\text { Gap 2: Quality } \\
\text { specification gap }\end{array}$} & BenMark and Venkatachari [30] & $\begin{array}{l}\text { Service organizations must design the overall customer journey } \\
\text { for robot service delivery. }\end{array}$ \\
\hline & Broadbent [68] & $\begin{array}{l}\text { Current technology has difficulty in achieving a high level } \\
\text { of autonomy. }\end{array}$ \\
\hline & Chen et al. [15] & There are gaps between existing techniques and expectations. \\
\hline & Kuo et al. [1] & $\begin{array}{l}\text { Problems can be solved with the advancement of robot } \\
\text { technologies and design. }\end{array}$ \\
\hline & McKinsey\&Company [59] & $\begin{array}{l}\text { Automation asks business leaders to redesign their processes } \\
\text { and organizations. }\end{array}$ \\
\hline & Tung and Au [21] & $\begin{array}{l}\text { Managers need to think through the tasks of the robot.Service } \\
\text { robots are technologies in the development stage; service robots } \\
\text { are not smart enough; service robots cannot complete some } \\
\text { service tasks. }\end{array}$ \\
\hline \multirow[b]{2}{*}{$\begin{array}{l}\text { Gap 3: Human service } \\
\text { delivery gap }\end{array}$} & Barrett et al. [47] & $\begin{array}{l}\text { In response to the robots' failures, technicians attended training } \\
\text { courses to learn how to repair and maintain the robots. }\end{array}$ \\
\hline & Tung and Au [21] & $\begin{array}{l}\text { Additional training for employees is required to communicate } \\
\text { and explain to customers the types of services that robots can or } \\
\text { cannot perform, and to provide technical and non-technical } \\
\text { assistance to customers when appropriate. }\end{array}$ \\
\hline
\end{tabular}


Table A1. Cont.

\begin{tabular}{|c|c|c|}
\hline Gap & Source & Viewpoint \\
\hline \multirow{7}{*}{$\begin{array}{l}\text { Gap 4: Service } \\
\text { communication gap }\end{array}$} & Belanche et al. [14] & $\begin{array}{l}\text { Robot notification makes it clear to customers that they are } \\
\text { interacting with robots }\end{array}$ \\
\hline & Čaić [41] & $\begin{array}{l}\text { Communicating robot roles shapes expectations } \\
\text { among customers. }\end{array}$ \\
\hline & Davenport et al. [49] & $\begin{array}{l}\text { If customers find out that they are interacting with a robot, they } \\
\text { may be uncomfortable, leading to negative consequences. }\end{array}$ \\
\hline & Forlizzi [33] & $\begin{array}{l}\text { Customers must be prepared to use robot service technically and } \\
\text { psychologically. }\end{array}$ \\
\hline & Kuipers [60] & $\begin{array}{l}\text { Robots need to assure customers that they are well intended and } \\
\text { trustworthy, and that they will do their best to minimize the risks. }\end{array}$ \\
\hline & Kuo et al. [1] & $\begin{array}{l}\text { Stimulating the fun and curiosity of customers can enhance the } \\
\text { promotion of service robots. }\end{array}$ \\
\hline & Qiu et al. [6] & Service robots of many companies are promotional gimmick. \\
\hline \multirow{3}{*}{$\begin{array}{l}\text { Gap 6: Manufacturers' } \\
\text { understanding gap }\end{array}$} & Kuo et al. [1] & $\begin{array}{l}\text { The success of robots depends on upstream } \\
\text { manufacturing support. }\end{array}$ \\
\hline & Paluch et al. [8] & $\begin{array}{l}\text { Service robots operate according to the algorithm written by an } \\
\text { engineer and follow a script. }\end{array}$ \\
\hline & Zalama et al. [39] & $\begin{array}{l}\text { Robot control systems require three levels of development } \\
\text { including hardware, functionality, and service. }\end{array}$ \\
\hline \multirow{3}{*}{ Gap 7: Technical gap } & Kabadayi et al. [9] & $\begin{array}{l}\text { Every robot that contributes to service delivery may fail at } \\
\text { some point. }\end{array}$ \\
\hline & Kuo et al. [1] & $\begin{array}{l}\text { Brain-drain of high-end talents; lack of talents in system } \\
\text { integration and professional training; inability to produce key } \\
\text { components of robots and to manufacture high-quality and } \\
\text { commercial robots. }\end{array}$ \\
\hline & Lu et al. [12] & It is common for robot services to fail. \\
\hline \multirow{7}{*}{$\begin{array}{l}\text { Gap 8: Service } \\
\text { coordination gap }\end{array}$} & Gursoy et al. [46] & $\begin{array}{l}\text { Customers will focus on whether AI devices can provide the } \\
\text { same or better level service than human employees. }\end{array}$ \\
\hline & Kabadayi et al. [9] & $\begin{array}{l}\text { Organizations can use robots to empower their service agents and } \\
\text { reduce their workload. }\end{array}$ \\
\hline & De Keyser et al. [25] & $\begin{array}{l}\text { The highest performance occurs when humans and machines } \\
\text { work together, rather than when machines completely } \\
\text { replace humans. }\end{array}$ \\
\hline & Paluch et al. [8] & $\begin{array}{l}\text { Robots' emotional representations are "fake" and manifest, not } \\
\text { real feelings. }\end{array}$ \\
\hline & Tung and Law [22] & $\begin{array}{l}\text { The success of service robots depends on effective } \\
\text { human-robot interaction. }\end{array}$ \\
\hline & van Doorn et al. [19] & $\begin{array}{l}\text { Humans and social robots will collaborate to provide more } \\
\text { services in the future. }\end{array}$ \\
\hline & Wirtz et al. [26] & $\begin{array}{l}\text { Customers are unlikely to respond to the emotions displayed by } \\
\text { robots in the same way that they respond to the emotions of } \\
\text { human employees. }\end{array}$ \\
\hline
\end{tabular}

\section{References}

1. Kuo, C.-M.; Chen, L.-C.; Tseng, C.-Y. Investigating an innovative service with hospitality robots. Int. J. Contemp. Hosp. Manag. 2017, 29, 1305-1321. [CrossRef]

2. van Pinxteren, M.M.E.; Wetzels, R.W.H.; Rüger, J.; Pluymaekers, M.; Wetzels, M. Trust in humanoid robots: Implications for services marketing. J. Serv. Mark. 2019, 33, 507-518. [CrossRef]

3. Pinillos, R.; Marcos, S.; Feliz, R.; Zalama, E.; Gómez-García-Bermejo, J. Long-term assessment of a service robot in a hotel environment. Robot. Auton. Syst. 2016, 79, 40-57. [CrossRef]

4. Qing-Xiao, Y.; Can, Y.; Zhuang, F.; Yan-Zheng, Z. Research of the localization of restaurant service robot. Int. J. Adv. Robot. Syst. 2010, 7, 227-238. [CrossRef]

5. Jörling, M. Service robots: Drivers of perceived responsibility for service outcomes. J. Serv. Res. 2019, 22, 404-420. [CrossRef]

6. Qiu, H.; Li, M.; Shu, B.; Bai, B. Enhancing hospitality experience with service robots: The mediating role of rapport building. J. Hosp. Mark. Manag. 2020, 29, 247-268. [CrossRef]

7. Zuboff, S. In the Age of the Smart Machine: The Future of Work and Power; Basic Books Inc.: New York, NY, USA, 1988; Volume 22, p. 154. 
8. Paluch, S.; Wirtz, J.; Kunz, W.H. Service robots and the future of service. In Marketing Weiterdenken-Zukunftspfade für eine marktorientierte Unternehmensführung, Bruhn, M.; Kirchgeorg, M., Burmann, C., Eds.; Springer Gabler-Verlag: Berlin/Heidelberg, Germany, 2020.

9. Kabadayi, S.; Ali, F.; Choi, H.; Joosten, H.; Lu, C. Smart service experience in hospitality and tourism services: A conceptualization and future research agenda. J. Serv. Manag. 2019, 30, 326-348. [CrossRef]

10. Molloy, M. Useless Robot Waiters Fired for Incompetence in China. Telegraph 2016. Available online: https://www.telegraph.co. uk/technology/2016/04/11/useless-robot-waiters-fired-for-incompetence-in-china (accessed on 5 March 2021).

11. Bolton, R.N.; McColl-Kennedy, J.R.; Cheung, L.; Gallan, A.; Orsingher, C.; Witell, L.; Zaki, M. Customer experience challenges: Bringing together digital, physical and social realms. J. Serv. Manag. 2018, 29, 776-808. [CrossRef]

12. Lu, V.N.; Wirtz, J.; Kunz, W.H.; Paluch, S.; Gruber, T.; Martins, A.; Patterson, P.G. Service robots, customers and service employees: What can we learn from the academic literature and where are the gaps? J. Serv. Theory Pract. 2020, 30, 361-391. [CrossRef]

13. Mende, M.; Scott, M.L.; van Doorn, J.; Grewal, D.; Shanks, I. Service robots rising: How humanoid robots influence service experiences and elicit compensatory consumer responses. J. Mark. Res. 2019, 56, 535-556. [CrossRef]

14. Belanche, D.; Casaló, L.V.; Flavián, C.; Schepers, J. Service robot implementation: A theoretical framework and research agenda. Serv. Ind. J. 2020, 40, 203-225. [CrossRef]

15. Chen, Y.; Wu, F.; Shuai, W.; Chen, X. Robots serve humans in public places-Kejia robot as a shopping assistant. Int. J. Adv. Robot. Syst. 2017, 14, 1-20. [CrossRef]

16. Huang, M.-H.; Rust, R.T. Artificial intelligence in service. J. Serv. Res. 2018, 21, 155-172. [CrossRef]

17. Parasuraman, A.; Zeithaml, V.A.; Berry, L.L. A conceptual model of service quality and its implications for future research. J. Mark. 1985, 49, 41-50. [CrossRef]

18. Lee, Y.-C.; Wang, Y.-C.; Chien, C.-H.; Wu, C.-H.; Lu, S.-C.; Tsai, S.-B.; Dong, W. Applying revised gap analysis model in measuring hotel service quality. SpringerPlus 2016, 5, 1191. [CrossRef]

19. van Doorn, J.; Mende, M.; Noble, S.M.; Hulland, J.; Ostrom, A.L.; Grewal, D.; Petersen, J.A. Domo Arigato Mr. roboto: Emergence of automated social presence in organizational frontlines and customers' service experiences. J. Serv. Res. 2017, 20, 43-58. [CrossRef]

20. Zhang, K.Z.K.; Benyoucef, M. Consumer behavior in social commerce: A literature review. Decis. Support. Syst. 2016, 86, 95-108. [CrossRef]

21. Tung, V.W.S.; Au, N. Exploring customer experiences with robotics in hospitality. Int. J. Contemp. Hosp. Manag. 2018, 30, 2680-2697. [CrossRef]

22. Tung, V.W.S.; Law, R. The potential for tourism and hospitality experience research in human-robot interactions. Int. J. Contemp. Hosp. Manag. 2017, 29, 2498-2513. [CrossRef]

23. Fan, A.; Wu, L.; Miao, L.; Mattila, A.S. When does technology anthropomorphism help alleviate customer dissatisfaction after a service failure?-The moderating role of consumer technology self-efficacy and interdependent self-construal. J. Hosp. Mark. Manag. 2020, 29, 269-290. [CrossRef]

24. Yu, C.-E. Humanlike robots as employees in the hotel industry: Thematic content analysis of online reviews. J. Hosp. Mark. Manag. 2020, 29, 22-38. [CrossRef]

25. De Keyser, A.; Köcher, S.; Alkire, L.; Verbeeck, C.; Kandampully, J. Frontline service technology infusion: Conceptual archetypes and future research directions. J. Serv. Manag. 2019, 30, 156-183. [CrossRef]

26. Wirtz, J.; Patterson, P.G.; Kunz, W.H.; Gruber, T.; Lu, V.N.; Paluch, S.; Martins, A. Brave new world: Service robots in the frontline. J. Serv. Manag. 2018, 29, 907-931. [CrossRef]

27. Xiao, L.; Kumar, V. Robotics for customer service: A useful complement or an ultimate substitute? J. Serv. Res. 2019, 24, 9-29. [CrossRef]

28. Čaić, M.; Mahr, D.; Oderkerken-Schröder, G. Value of social robots in services: Social cognition perspective. J. Serv. Mark. 2019, 33, 463-478. [CrossRef]

29. Beane, M. Learning to work with intelligent machines. Harvard Bus. Rev. 2019, 97, 140-148.

30. BenMark, G.; Venkatachari, D. Messaging apps are changing how companies talk with customers. Harvard Bus. Rev. 2016, 23, 2-4.

31. Brooks, R. More robots won't mean fewer jobs. Harvard Bus. Rev. 2014, 2-4. Available online: https://hbr.org/amp/2014/06/ more-robots-wont-mean-fewer-jobs (accessed on 5 March 2021).

32. Davenport, T.H.; Ronanki, R. Artificial intelligence for the real world. Harvard Bus. Rev. 2018, 96, 109-116.

33. Forlizzi, J. How robots will work with us isn't only a technological question. Harvard Bus. Rev. 2014, 2-3. Available online: https:/ /hbr.org/2014/03/how-robots-will-work-with-us-isnt-only-a-technological-question (accessed on 18 August 2020).

34. Zeller, F.; Smith, D.H. What a hitchhiking robot can teach us about automated coworkers. Harvard Bus. Rev. 2014, 2-5. Available online: https://hbr.org/2014/12/what-a-hitchhiking-robot-can-teach-us-about-automated-coworkers (accessed on 5 March 2021).

35. Lacity, M.C.; Willcocks, L.P. A new approach to automating services. MIT Sloan Manag. Rev. 2016, 58, 40-49.

36. Ransbotham, S.; Kiron, D.; Gerbert, P.; Reeves, M. Reshaping business with artificial intelligence: Closing the gap between ambition and action. MIT Sloan Manag. Rev. 2017, 59. Available online: https://max.book118.com/html/2017/1217/144535498 shtm (accessed on 5 March 2021). 
37. ISO 8373:2021, Robotics—Vocabulary. Available online: https://www.iso.org/obp/ui/\#iso:std:iso:8373:ed-3:v1:en (accessed on 16 February 2022).

38. Kwak, H.-J.; Park, G.-T. Study on the mobility of service robots. Int. J. Eng. Technol. Innov. 2012, 2, 97-112.

39. Zalama, E.; García-Bermejo, J.G.; Marcos, S.; Domínguez, S.; Feliz, R.; Pinillos, R.; López, J. Sacarino, a Service Robot in a Hotel Environment. In ROBOT2013: First Iberian Robotics Conference; Armada, M.A., Sanfeliu, A., Ferre, M., Eds.; Springer International Publishing: New York, NY, USA, 2014; pp. 3-14.

40. Zeithaml, V.A.; Berry, L.L.; Parasuraman, A. The nature and determinants of customer expectations of service. J. Acad. Mark. Sci. 1993, 21, 1-12. [CrossRef]

41. Čaić, M. Designed to Serve: Social Robots in Value Networks; Off Page: Amsterdam, The Netherlands, 2019.

42. Dautenhahn, K. Embodiment and interaction in socially intelligent life-like agents. In Computation for Metaphors, Analogy and Agents; Nehaniv, C., Ed.; Springer: Berlin/Heidelberg, Germany, 1999; Volume 1562, pp. 102-141.

43. Welch, C. SoftBank's Humanoid Robot Pepper is Getting a Job at Pizza Hut. Verge. Available online: https://www.theverge.com/ circuitbreaker/2016/5/24/11758978/softbank-pepper-humanoid-robot-pizza-hut-mastercard (accessed on 5 March 2021).

44. Wykowska, A.; Chellali, R.; Al-Amin, M.; Muller, H. Implications of robot actions for human perception. How do we represent actions of the observed robots? Int. J. Soc. Robot. 2014, 6, 357-366. [CrossRef]

45. Thrun, S. Toward a framework for human-robot interaction. Hum.-Comput. Interact. 2004, 19, 9-24.

46. Gursoy, D.; Chi, O.H.; Lu, L.; Nunkoo, R. Consumers acceptance of artificially intelligent (AI) device use in service delivery. Int. J. Inf. Manag. 2019, 49, 157-169. [CrossRef]

47. Barrett, M.; Oborn, E.; Orlikowski, W.J.; Yates, J. Reconfiguring boundary relations: Robotic innovations in pharmacy work. Organ. Sci. 2012, 23, 1448-1466. [CrossRef]

48. Barrett, M.; Davidson, E.; Prabhu, J. Service innovation in the digital age: Key contributions and future directions. MIS Q. 2015, 39, 135-154. [CrossRef]

49. Davenport, T.; Guha, A.; Grewal, D.; Bressgott, T. How artificial intelligence will change the future of marketing. J. Acad. Mark. Sci. 2020, 48, 24-42. [CrossRef]

50. Hochman, D. This $\$ 25,000$ Robotic Arm Wants to Put your Starbucks Barista out of Business. CNBC. Available online: https: / / www.cnbc.com/2018/05/08/this-25000-robot-wants-to-put-your-starbucks-barista-out-of-business.html (accessed on 5 March 2021).

51. Cooper, D. Lowe's Innovation Labs Redefine Retail with Robots and VR. Engadget. Available online: https://www.engadget. com/2015-01-08-we-meet-lowes-diy-robot.html (accessed on 5 March 2021).

52. Gustafsson, A.; Högström, C.; Radnor, Z.; Friman, M.; Heinonen, K.; Jaakkola, E.; Mele, C. Developing service research-Paving the way to transdisciplinary research. J. Serv. Manag. 2016, 27, 9-20. [CrossRef]

53. Holley, P.; Eltagouri, M. 'Flippy', the Fast Food Robot, Temporarily Decommissioned for Being too Slow. Wash. Post. Available online: https://www.washingtonpost.com/news/innovations/wp/2018/03/05/meet-flippy-a-burger-flipping-robotalternative-to-wage-earning-workers (accessed on 5 March 2021).

54. Nichols, G. Robot Fired from Grocery Store for Utter Incompetence. ZDNet. Available online: https://www.zdnet.com/article/ robot-fired-from-grocery-store-for-utter-incompetence (accessed on 5 March 2021).

55. Yu, C.-E. Humanlike robot and human staff in service: Age and gender differences in perceiving smiling behaviors. In Proceedings of the 2018 7th International Conference on Industrial Technology and Management (ICITM), Oxford, UK, 7-9 March 2018.

56. Grandey, A.A.; Fisk, G.M.; Mattila, A.S.; Jansen, K.J.; Sideman, L.A. Is "service with a smile" enough? Authenticity of positive displays during service encounters. Organ. Behav. Hum. Decis. Process. 2005, 96, 38-55. [CrossRef]

57. Verhoef, P.C.; Business, G.; Lemon, K.N.; Parasuraman, A.; Roggeveen, A.; Tsiros, M.; Schlesinger, L.A. Customer experience creation: Determinants, dynamics and management strategies. J. Retail. 2009, 85, 31-41. [CrossRef]

58. Pino, M.; Boulay, M.; Jouen, F.; Rigaud, A.-S. 'Are we ready for robots that care for us?' Attitudes and opinions of older adults toward socially assistive robots. Front. Aging Neurosci. 2015, 7, 141. [CrossRef] [PubMed]

59. McKinsey\&Company. A Future that Works: Automation, Employment, and Productivity. Available online: https://www. mckinsey.com/featured-insights/digital-disruption/harnessing-automation-for-a-future-that-works/de-de (accessed on 5 March 2021).

60. Kuipers, B. Toward Morality and Ethics for Robots. In 2016 AAAI Spring Symposium Series; AAAI Publications: Palo Alto, CA, USA, 2016; pp. 40-57.

61. Rosene, F. Complacency and service quality: An overlooked condition in the gap model. J. Retail. Consum. Serv. 2003, 10, 51-55. [CrossRef]

62. Holden, R.J.; Karsh, B.T. The technology acceptance model: Its past and its future in health care. J. Biomed. Inform. 2010, 43, 159-172. [CrossRef] [PubMed]

63. Johnson, D.G.; Verdicchio, M. AI anxiety. J. Assoc. Inf. Sci. Technol. 2017, 68, 2267-2270. [CrossRef]

64. Andreassen, T.W.; van Oest, R.D.; Lervik-Olsen, L. Customer inconvenience and price compensation: A multiperiod approach to labor-automation trade-offs in services. J. Serv. Res. 2018, 21, 173-183. [CrossRef]

65. Prosser, M. Soon We'll All Love Robots the Way Japan Loves Robots. Singul. Hub. Available online: https://singularityhub.com/ 2016/10/20/soon-well-all-love-robots-the-way-japan-loves-robots (accessed on 5 March 2021). 
66. Bartneck, C.; Kulić, D.; Croft, E.; Zoghbi, S. Measurement instruments for the anthropomorphism, animacy, likeability, perceived intelligence, and perceived safety of robots. Int. J. Soc. Robot. 2009, 1, 71-81. [CrossRef]

67. Virabhakul, V.; Huang, C. Effects of service experience on behavioral intentions: Serial multiple mediation model. J. Hosp. Mark. Manag. 2018, 27, 997-1016. [CrossRef]

68. Broadbent, E. Interactions with robots: The truths we reveal about ourselves. Annu. Rev. Psychol. 2017, 68, 627-652. [CrossRef]

69. Tavakoli, R.; Mura, P. Netnography in tourism-beyond web 2.0. Ann. Tour. Res. 2018, 73, 190-192. [CrossRef]

70. Shah, H.; Warwick, K.; Vallverdú, J.; Wu, D. Can machines talk? comparison of Eliza with modern dialogue systems. Comput. Hum. Behav. 2016, 58, 278-295. [CrossRef]

71. Wirtz, J.; Jerger, C. Managing service employees: Literature review, expert opinions, and research directions. Serv. Ind. J. 2016, 36, 757-788. [CrossRef]

72. Jones, K.S.; Schmidlin, E.A. Human-robot interaction: Toward usable personal service robots. Rev. Hum. Factors Ergon. 2011, 7, 100-148. [CrossRef]

73. Nam, K.; Dutt, C.S.; Chathoth, P.; Daghfous, A.; Khan, M.S. The adoption of artificial intelligence and robotics in the hotel industry: Prospects and challenges. Electron. Mark. 2020, 31, 553-574. [CrossRef]

74. Pandey, N.; Jha, S.; Rai, V. Ayushman Bharat: Service adoption challenges in universal healthcare system. South Asian J. Bus. Manag. Cases 2021, 10, 35-49. [CrossRef]

75. Ivanov, S.; Webster, C.; Berezina, K. Adoption of robots and service automation by tourism and hospitality companies. In Proceedings of the INVTUR 2017, Aveiro, Portugal, 17-19 May 2017. 